\title{
Ginette Rodger: On Knowledge and Influence
}

Ginette L. Rodger, $\mathrm{RN}, \mathrm{PhD}$, was recognized this Fall with an Award of Excellence in Nursing Leadership by the Ontario Hospital Association. She is the vice-president of professional practice and chief nursing executive at the Ottawa Hospital, the University of Ottawa Heart Institute and the Rehabilitation Centre,

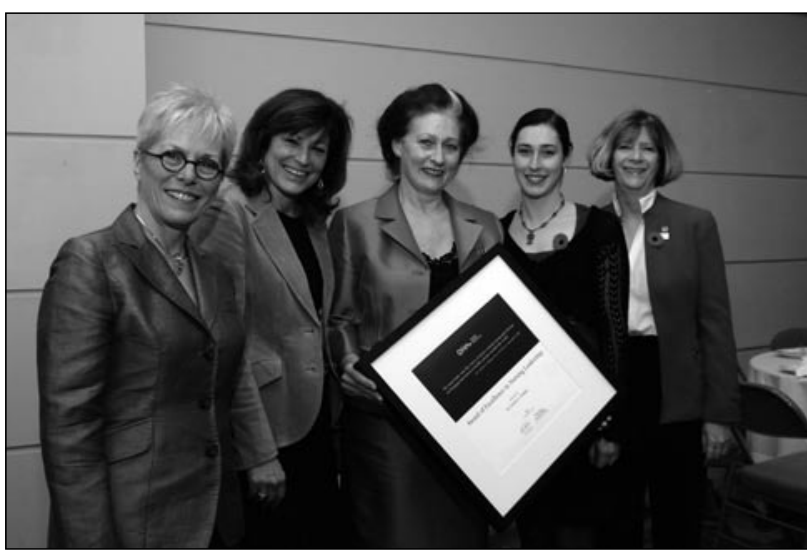

Ginette Rodger (holding award) with daughter Sabrina (immediate right). Also in photo are OHA Nursing Leadership award winners Mary Ferguson-Paré (left), Shirlee Sharkey and Esther Green (far right). and past president of the Canadian Nurses

Association. She completed a $\mathrm{PhD}$ in Nursing at the University of Alberta in 1995. Prior to 1989, she was concurrently the executive director of the Canadian Nurses Association (CNA), secretary treasurer of the Canadian Nurses Foundation and secretary treasurer of the Canadian Nurses Protective Society. She has had diversified experience in management, education, research and clinical nursing.

Dr. Rodger served on commissions and boards of directors of many health, nursing, political and educational organizations by serving as the chair of the Canadian Council on Hospital Accreditation and of the National Health Care Committee, St-John Ambulance; and as a member of the Medical Research Council of Canada; 
the Health and Community Services Committee, the Canadian Red Cross Society; and the Professional Service Committee of the Victorian Order of Nurses. She served as a successful strategist for many projects, including the redesigning of the Centre for Gerontology at the University of Alberta; the designing of a Centre of Excellence for Diabetes Education in the Alberta Capital Region for the Consortium of Health Services Education and Research; the funding of the first $\mathrm{PhD}$ program in Nursing in Canada at the University of Alberta; legislative changes to the Canada Health Act; and modification of the Primary Health Care agenda of the World Health Organization.

\section{What do you feel are the great chal- lenges facing nursing leaders today?}

I would like to focus on two interrelated and critical challenges - the development of leaders and health human resources.

Nurses are moving into a new era, the information age, which is really driven by knowledge and technology. And, in light of those drivers, we need to look at how work is organized. People now work in teams that are quasi-autonomous with very little integration between them. These teams usually span multiple sites and they are custom designed to suit the purpose, so there's less standardization. People are joining teams, then detaching and joining another teams, and back and forth. So, the issue of networks and sets of teams are integral to the way work is now organized.
However, in an aging nursing workforce, many nurses practising today were educated during the industrial age, which favoured a more top-down type of organization. Now, as we move into the information age, the focus is on teams, with far fewer points of control. So, the big challenge is to help nurses grow their leadership ability instead of routinely expecting to execute the orders of their positional leaders.

Very often, we equate leadership with management, which, of course, are two different concepts. Leadership is really the ability to influence and persuade others toward a common goal. Our big challenge right now is that probably $90 \%$ of the nurses that are in clinical areas come from the era of "following positional leaders or managers."

We need to turn all this on its side. It's a huge challenge. In Canada, nursing is a profession of more than 300,000 people. We need to grow nurses' leadership abilities because our ability to face the challenges of tomorrow is dependent on exercising leadership at all levels. If nursing is to make its full contribution, nurses will have to be able to influence, persuade and move others toward a goal.

If you look at preparing leaders for tomorrow, we are going to need to really push the development of leadership at all levels. When new clinicians enter the workforce, they have learned how to persuade, how to influence and how to move a team toward a goal. The current generation of nurses needs to be provided the opportunity to relearn or develop an ability to do this.

I would say that the second greatest 
challenge we're facing in nursing is in human resources. This is a system-wide challenge that is already affecting us all. And, we know that by 2016 , we'll be about $40 \%$ short in the supply of nurses compared with now. This is based on looking at the retirement age, as well as the rate of entry into the profession. It's not because people don't want to enter nursing; in fact, we have more candidates than we have spaces to accommodate them. The issue is related to poor policy decisions made in the late ' 90 s that we are paying for now. In essence, a generation of nurses is missing.

This is going to be the most significant shortage that we have ever, ever experienced. And the consequences of it are going to be huge because access to care is a major issue for the public and for government. Increasing access is a political agenda; yet, because of the shortage of healthcare professionals, we are going to be closing beds and services to the public. So, it's going to be a nurses' market, and nurses are going to go wherever there is a nurse-friendly environment to work. And this is not only a Canadian issue, it's worldwide. For example, by 2020, the United States will be short about 1,000,000 nurses.

So, the challenge is this: since we know what is coming at us and what that issue is, what do we do to minimize the impact? We need to look at supply side issues like increasing the number of students and trying to keep nurses working longer in the system. We also have to look at the demand side. We know that there is going to be an increased demand, which will make the deficit even greater.
We also need to look at how we can better utilize the services of nurses. This is a group of professionals who have a lot of knowledge. We should be using them where we need their knowledge. We shouldn't be using nurses to do things that other people could do.

\section{You are referring to defining the role of nurses?}

Oh, absolutely. We require a wholesale redesign and challenge to the way things are done. That will take a lot of foresight and innovation - to be able to see how we will ensure health services to the public.

So, I would say, those are the two greatest issues: the growth of the leadership, particularly with the clinical nurses, and the human resources. As you can see, if we have a good cadre of leaders in all domains of practice, then it will be easier to do all that needs to be done around the nursing human resources.

\section{What do you think are the key attributes of successful leaders?}

A nurse leader needs to be a visionary, but that vision needs to be grounded in professional values - compassion, caring, knowledge and evidence. When you look at redesigning, revisiting, reengineering and innovating, the leaders that have a vision and are grounded in the values of the profession are able to be the most influential.

A second attribute of a successful leader is knowledge. If you think of a managerial leader, as in my role as a chief nurse, the role is mostly managing. So, I need to be at the top of my game, at the leading edge of the knowl- 
edge in my area. For instance, I need to be up on knowledge such as, How do you lead groups? How do you reorganize infrastructures and processes, track goals and outcomes and things like that? If you are a clinical nurse, knowledge would be around your area of specialty and practice - because with knowledge comes influence.

A third attribute is courage. Nurse leaders need to be courageous. In a time of so much movement in society, when leaders cannot see precisely what the future looks like, they need to be driven by a vision; they need to have the courage to speak out about beliefs and values.

A fourth attribute for successful leaders is visibility. In fact, studies of the magnet hospitals in the United States have shown that the visibility of leaders is the real magnetic element. People like to see the others who are exercising their leadership - they want them to be visible models.

The last attribute that is absolutely critical is a commitment to teamwork. Today, the issue of working with and for people is absolutely central to anything we do because - as I mentioned earlier about the nature of the work - it's now about teams: joining a team, letting go of a team, joining another team. It's all based on that.

\section{So, when you see these attributes in an emerging leader, how do you nurture them? Or how can they be nurtured?}

Here at The Ottawa Hospital, we're putting a nursing leadership team together based on the four domains of nursing - clinical practice, research, education and administration. We have redesigned our professional practice environment to put together a group of people interested in a topic. We go through all the evidence there is out there and combine what we know. Then we start addressing the question, trying various solutions.

Because, of the way we define leadership, the team is constituted with clinicians, educators, researchers and administrators. The exercise, according to our terms of reference, is about growing leaders, not followers. It's shattering the idea of followers.

Our approach is to identify people who demonstrate attributes of influence and persuasion. This really constitutes the first wave of leaders to invest in. They then invest in the second wave, and the third wave.

\section{So, it's mentoring?}

It would be almost like layered mentorship. Who are the people who we can invest in for the first layer, and what do we do for them to grow their leadership and to maintain it so that they feel sustained and valued? So, you invest in that first wave, and then it's up to them to invest in the second wave.

We have done a lot of redesign that is totally based on growing clinical leaders. For example, at every unit, we have developed unit clinical practice committees. These committees must be chaired by clinical nurses, not by the manager or the educator. There are usually three nurses who are involved in exercising their leadership and moving that forward. And, out of that 
unit, come two other nurses: a representative and an alternate, who come into a corporate forum for clinical nursing. It is chaired and co-chaired by clinical nurses drawn from across the organization. So, out of each unit, five people are already in an infrastructure that facilitates the growth of leadership in the clinical nurses. They make real decisions that change big things in the hospital that can cost a lot of dollars, and they have become very influential. So, it's a training ground for leadership.

\section{What kind of outcomes have you seen?}

Extraordinary outcomes. When we started this, we had 12 and $13 \%$ vacancies. We were then down to $5 \%$, and last year we were down to $2 \%$. And our retention rate, instead of being like the industry average at 12 to $20 \%$, is below $8 \%$.

Let's talk a bit about your career. What or who have been the big influences in your career?

There have been many, many influences. There were several individuals who created opportunities that provided the support and allowed me to nurture the natural abilities.

As far as issues of vision and values, I can still remember, a director of nursing who was very visionary and she certainly marked my career.
But I've certainly been blessed because I've had a lot of opportunities and I've worked with a lot of fantastic people over the time. It validated the importance of being able to influence and persuade others to move toward a goal.

\section{Is there a key piece of advice that you have for aspiring nursing leaders?}

I can think of two things. One is to live your dream. You know, if there is something that you want to do, plan it and do it. Don't wait for anybody. Don't plead circumstance. Just look at the opportunities, and live the dream you have. In nursing, the beauty is that the profession deals with the whole human being - bio, psycho, social and spiritual. We deal with the whole person all the time, and we do it in every environment you can think of. You can be in a hospital, you can be in a school, you can be in an inner city, you can be on an oil rig, you can be on the ski hills, you can be anywhere.

The other thing I would say to a nurse leader is to learn. Learn all the time because the whole era is driven by knowledge. The more knowledgeable you are, the more it increases your realm of influence because knowledge is a leveller. So, the more you know, the more effective a leader you will be in your domain. 